Int. J. Electrochem. Sci., 11 (2016) 3238 - 3259

\title{
A Novel Study on Separate and Combined Effects of the Cathodic Protection and Elastic Stress on Corrosion Behaviors of the Q235B Steel in 3.5\% NaCl Aqueous Solution
}

\author{
Hong-Qi Yang, You Wang, San-Shan Tu, Yi-Min Li, Yi Huang ${ }^{*}$ \\ School of Naval Architecture, Dalian University of Technology, Dalian 116024, Liaoning, China \\ *E-mail: huangyi@dlut.edu.cn
}

doi: $10.20964 / 110403238$

Received: 3 December 2015 / Accepted: 21 December 2015 / Published: 1 March 2016

\begin{abstract}
The separate and combined effects of cathodic protection potential and macro-elastic stress on corrosion behaviors of $\mathrm{Q} 235 \mathrm{~B}$ steel in an aerated 3.5\% $\mathrm{NaCl}$ aqueous solution were investigated through measurements of corrosion potential, potentiodynamic polarization characteristics, potentiostatic current and electrochemical impedance spectra (EIS). Thermodynamic and kinetic analyses as well as experimental results show that the surface energy increment due to the elastic stress is sufficient to cause the negative direction shifted of the corrosion potential and enhance the corrosion rate of the steel significantly. The transfer resistance $\left(R_{c t}\right)$ with different elastic stress levels and various cathodic polarization potentials was obtained by fitting the EIS data with the software ZSimpWin. The relationship between $R_{c t}$ and cathodic polarization potential under different stress levels was also investigated. In the cathodic polarization region, both the optimum protection potential $\left(E_{o p t}\right)$ and hydrogen evolution potential $\left(E_{H}\right)$ could be determined by the relationship curves of $R_{c t}$ and cathodic polarization potential. The results indicate that $R_{c t}$ decreases significantly with increasing of elastic stress, particularly near the optimum protection potential, and also the optimum protection potential decreases linearly with the increasing of elastic stress. Some concluding remarks achieved in this study provide important recommendations that the corrosion enhancement due to the elastic stress on structural surface should be considered in safety design of marine structures, and meanwhile provide an insight into the optimization of cathodic protection system design.
\end{abstract}

Keywords: Q235B steel; Cathodic protection; EIS; Effects of stress on corrosion behaviors.

\section{$\underline{\text { FULL TEXT }}$}

(C) 2016 The Authors. Published by ESG (www.electrochemsci.org). This article is an open access article distributed under the terms and conditions of the Creative Commons Attribution license (http://creativecommons.org/licenses/by/4.0/). 